\title{
CIRCLING BEHAVIOR IN OLD RATS AFTER UNILATERAL INTRANIGRAL INJECTION OF 1-METHYL-4-PHENYL-1,2,3,6-TETRAHYDROPYRIDINE (MPTP)
}

\author{
K. W. Lange \\ Laboratory of Psychobiology, Institute of Psychology, \\ University of Düsseldorf, 4000 Düsseldorf, F.R.G. *
}

(Received in final form August 25, 1989)

\begin{abstract}
Summary
Old and young adult rats received unilateral injections of MPTP or saline into the substantia nigra. Unilateral injection of MPTP in old rats induced ipsiversive circling on day 1 and day 7 after the injection; contraversive circling behavior was induced in MPTP-treated rats by systemic administration of apomorphine. Young rats showed ipsiversive circling on day 1 but not on day 7 after the injection; administration of apomorphine did not induce contraversive circling. On day 10 after the injection of MPTP, the concentration of D-2 receptors in the striatum of the injected hemisphere of old rats was increased by about $25 \%$ compared with the striatum of old rats with saline injection and of young rats with MPTP or saline injections. These results suggest that MPTP exerts neurotoxic effects on the nigrostriatal dopaminergic system of old rats and produces supersensitive dopamine receptors in the ipsilateral denervated striatum.
\end{abstract}

1-Methyl-4-phenyl-1,2,3,6-tetrahydropyridine (MPTP) causes destruction of dopaminergic neurons in the substantia nigra pars compacta in humans and non-human primates and induces an irreversible syndrome with behavioral, neurochemical and histopathological changes similar to idiopathic Parkinson's disease (1-3). The brains of rodents, especially of rats, are more resistant to the neurotoxicity of MPTP than the brains of primates. Initial attempts to induce pathological effects in rats by systemic administration of MPTP were not successful $(4,5)$. Intranigral injection of MPTP in the rat failed to produce lasting damage to the dopaminergic nigral neurons $(5,6)$ or lasting behavioral effects $(7)$.

* Present address: University Department of Neurology, Institute of Psychiatry, Denmark Hill, London SE5 8AF, U.K. 
Evidence is evolving that the neurotoxic effects of MPTP are age-dependent. While MPTP does little damage to neurons in the young mature mouse, it does have severe effects in the old mouse on both visible signs of movement disability and anatomical damage to the substantia nigra (8). The present study attempted to determine the behavioral effects of unilateral injection of MPTP into the substantia nigra in old rats in comparison with young adult rats.

Circling was the behavioral model used for the assessment of dopaminergic lesions in the substantia nigra. Circling behavior in the rat can be produced by destruction of one ascending nigrostriatal dopamine pathway and is believed to reflect an imbalance of dopaminergic activity in the striata. The rat turns towards the side of the lesion, i.e. away from the hemisphere of higher striatal dopaminergic activity. After systemic administration of dopamine agonists circling away from the hemisphere with destroyed nigrostriatal pathway appears due to supersensitivity of the denervated striatal dopamine receptors $(9,10)$.

\section{Materials and Methods}

Male BD IX rats had chronic guide cannulae implanted to allow unilateral injection into the substantia nigra. The guide cannulae were unilaterally implanted $2.0 \mathrm{~mm}$ dorsal to the substantia nigra under equithesin anesthesia using a stereotaxic instrument (David Kopf Instruments, Palo Alto, $\mathrm{CA})$. Young adult rats aged 4 to 5 months $(\mathrm{N}=6)$ and old rats aged 22 to 24 months $(\mathrm{N}=$ 7) received a unilateral injection of $50 \mu \mathrm{g} / 1 \mu \mathrm{l}$ MPTP (Research Biochemicals Inc., Wayland, MA) through an inner injection cannula which extended $2.0 \mathrm{~mm}$ beyond the end of the guide cannula. MPTP was injected over a period of 5 minutes; the injection cannula was left in place for an additional 60 seconds following the injection to ensure adequate diffusion and to minimize spread of solution up through the cannula tract. Young adult $(N=6)$ and old control rats $(N=7)$ received a saline solution which was equimolar to the MPTP solution. The stereotaxic coordinates for the intranigral injection corresponded to König and Klippel (11) coordinates: A $2420, \mathrm{~V}-2.4, \mathrm{~L} 1.6$.

Circling behavior in both groups was automatically recorded with the animals in a square box $(0.5 \times 0.5 \mathrm{~m})$. The number of rotations directed either ipsiversive or contraversive with respect to the injected hemisphere were measured. Recordings were made for 30 minutes on day 1 following intranigral injection and on day 7 for 30 minutes before and for 30 minutes after subcutaneous injection of apomorphine $(0.5 \mathrm{mg} / \mathrm{kg}$ body weight; Woelm Pharma, Eschwege, F.R.G.).

On day 10 after injection of MPTP or saline, rats were killed by cervical dislocation and decapitation and the brains rapidly removed onto ice. The striatum was dissected out and placed into ice-cold $50 \mathrm{mM}$ Tris-IICl buffer ( $\mathrm{pH}$ 7.6). Spccific binding of $\left[{ }^{3} \mathrm{H}\right]$ spiperone (Amersham International, U.K.; $18-19 \mathrm{Ci} / \mathrm{mmol}$; concentrations between 0.1 and $1.0 \mathrm{nM}$ ) in tissue homogenates of the striatum of the injected hemisphere was determined by the method of Leysen et al. (12), in a final tissue suspension of 1 in $800 \mathrm{w} / \mathrm{v}$ using an incubation buffer containing 50 $\mathrm{mM}$ Tris- $\mathrm{HCl}$ and $120 \mathrm{mM} \mathrm{NaCl}(\mathrm{pH} 7.6)$. Nonspecific binding of $\left[{ }^{3} \mathrm{H}\right]$ spiperone was defined by the incorporation of $10^{-5} \mathrm{M}( \pm)$-sulpiride (Delagrange, Paris, France). All determinations were carried out in triplicate. The number of binding sites $\left(\mathrm{B}_{\max }\right)$ and the apparent equilibrium constant $\left(\mathrm{K}_{\mathrm{d}}\right)$ were determined by Eadie-Hofstee analysis. 
No. of rotations per $\mathbf{3 0}$ minutes

\section{YOUNG ADULT RATS}

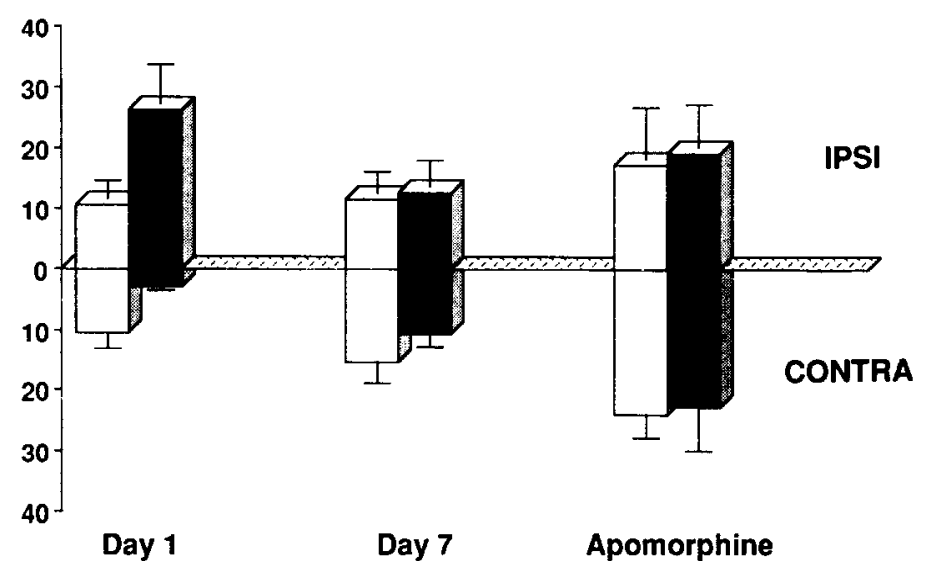

No. of rotations per 30 minutes

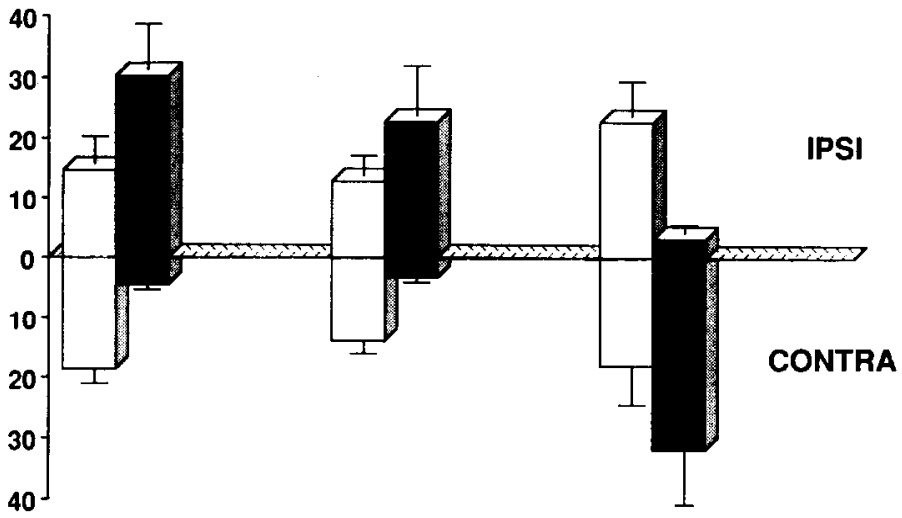

Day 1

Day 7

Apomorphine

FIGURE 1

Ipsiversive (IPSI) and contraversive (CONTRA) circling 1 day and 7 days after unilateral injection of MPTP (black bars) or saline (white bars) into the substantia nigra of young adult and old rats and apomorphine-induced circling on day 7 after injection (means \pm s.e.m.). 


\section{$\underline{\text { Results }}$}

Unilateral intranigral injection of MPTP induced strong ipsiversive circling (i.e. towards the side of injection) in both young adult and old rats on the first day after injection (see fig. 2). On day 7 after the MPTP injection, spontaneous ipsiversive circling behavior was still present in old rats whereas young adult rats did not circle preferentially in either direction. Neither young adult nor old control rats showed asymmetry in circling behavior. Old rats with unilateral MPTP injections circled contraversively when injected with apomorphine 7 days after the injection; young adult rats did not show contraversive circling after administration of apomorphine (see fig. 1).

Ten days after the unilateral intranigral injection of MPTP or saline, the concentration $\left(\mathrm{B}_{\max }\right)$ of striatal D-2 receptors identified by $\left[{ }^{3} \mathrm{H}\right]$ spiperone in the injected hemisphere of old rats with MPTP injection was substantially increased compared with the injected hemisphere of old rats with saline injection and of young rats with MPTP or saline injections (see fig. 2). The affinity $\left(\mathrm{K}_{\mathrm{d}}\right)$ of $\mathrm{D}-2$ receptors was not affected.

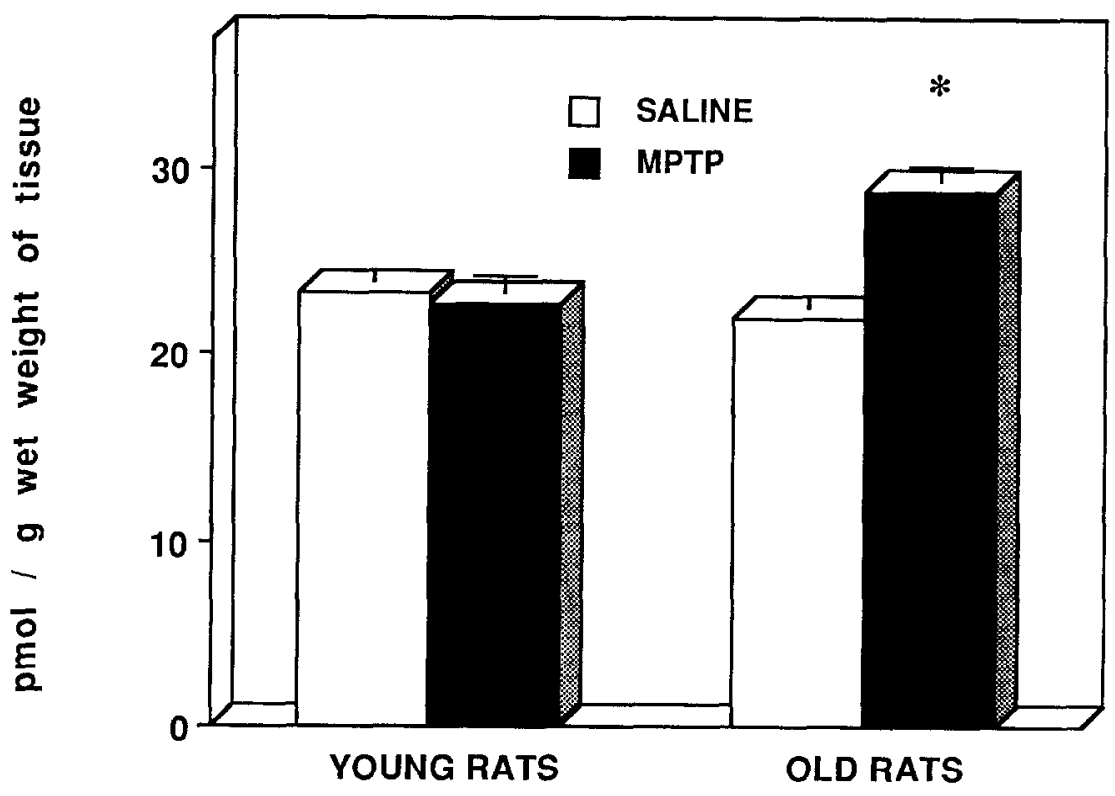

FIGURE 2

D-2 receptor densities $\left(B_{\max }\right.$, means \pm s.e.m.) in the striatum of the injected hemisphere of young adult and old rats 10 days after unilateral intranigral injection of MPTP (black bars) or saline (white bars); in comparison with the control group: $* \mathrm{p}<0.05$, Mann-Whitney U-test. 


\section{Discussion}

In young adult rats unilateral injection of MPTP into the substantia nigra induced ipsiversive circling of short duration and after systemic administration of the dopamine agonist apomorphine the rats did not circle preferentially in either direction. Thus, MPTP has only a short lasting depressive effect on dopaminergic neurons in young rats. In old rats ipsiversive turning could be observed for at least one week after the injection of MPTP; the administration of apomorphine induced contraversive turning. D-2 receptor density in the striatum of the injected hemisphere was higher after MPTP injection than after saline injection. These results suggest that MPTP exerts neurotoxic actions on the nigrostriatal dopaminergic system of old rats and induces supersensitivity of the dopamine receptors in the denervated striatum on the side of MPTP injection.

The present results suggest that the effects of unilateral intranigral injection of MPTP are age-dependent and that previous attempts to induce lasting changes by MPTP in rats were unsuccessful because young animals were used. Other studies also provide evidence that the effects of MPTP increase with age. Neonatal rats are resistant to the dopamine-depleting effects of MPTP whereas the toxin produces a $65 \%$ striatal dopamine depletion in young adult rats (13). Extensive degeneration of nigral neurons is found in older but not younger mice given MPTP (14). The ventral tegmental area and the locus coeruleus of old but not young mice are affected by MPTP (8); the distribution of lesions in older mice is much closer to the pathological changes seen in Parkinson's disease.

The neurotoxic effects of MPTP have been shown to be dependent on its conversion to 1-methyl-4-phenylpyridine (MPP+) by monoamine oxidase B (MAO B; 15,16). The enhanced toxicity of MPTP in older animals can be due to increased sensitivity of nigrostriatal neurons of older animals to the effects of MPTP or to the presence of greater quantities of MPTP or its metabolite $\mathrm{MPP}^{+}$in the target area. No differences in the striatal dopamine depletion induced by intracerebroventricular administration of $\mathrm{MPP}^{+}$are observed between young and old mice (17), suggesting that old nigrostriatal neurons are not more sensitive to $\mathrm{MPP}^{+}$and that higher concentrations of the toxin account for the age-related effects. Thus, in the present study the enhanced MPTP effects in older animals are likely to be the result of increased MPP+ concentrations in the substantia nigra. A possible explanation for the age-dependence of MPTP toxicity is the increase of MAO B activity in the brain with age. In the rat central MAO B activity increases at least over the first two years of life (18). In the mouse striatal MPP concentrations increase directly with the age of the animals injected with MPTP (19).

MPTP-induced neurotoxicity in animals, especially in primates, has provided a very useful model of Parkinson's disease. Since Parkinson's disease is an age-related neurodegenerative disorder usually occurring in the sixth or seventh decade of life, it might be interesting to further investigate the effects of MPTP in old rats and ascertain whether or not the old rat can be used as a model.

\section{Acknowledgements}

The author was supported by the Deutsche Forschungsgemeinschaft and is grateful to Professor K. T. Kalveram for his help in carrying out this study. 


\section{References}

1. J.W. LANGSTON, P. BALLARD, J.W. TETRUD and I. IRWIN, Science 219 979-980 (1983).

2. R.S. BURNS, C.C. CHIUEH, S.P. MARKEY, M.H. EBERT, D.M. JACOBOWITZ and I.J. KOPIN, Proc. Natl. Acad. Sci. U.S.A. 80, 4546-4550 (1983).

3. J.W. LANGSTON, in C.D. MARSDEN and S. FAHN (eds.), Movement Disorders 2, pp. 73-90, Butterworths, London (1987).

4. S. BOYCE, E. KELLY, C. REAVILL, P. JENNER and C.D. MARSDEN, Biochem. Pharmacol. 33 , 1747-1752 (1984).

5. C.C. CHIUEH, S.P. MARKEY, R.S. BURNS, J.N. JOHANNESSEN, A. PERT and I.J. KOPIN, Eur. J. Pharmacol. 100, 189-194 (1984).

6. A.J. BRADBURY, B. COSTALL, A.M. DOMENEY, P. JENNER, M.E. KELLY, C.D. MARSDEN and R.J. NAYLOR, Nature $\underline{319}$, 56-57 (1986).

7. H. WELZL and K.W. LANGE, Eur. J. Pharmacol. 132, 295-297 (1986).

8. M.GUPTA, B.K. GUPTA, R. THOMAS, V. BRUEMMER, J.R. SLADEK, Jr. and D.L. FELTEN, Neurosci. Lett. 70, 326-331 (1986).

9. U. UNGERSTEDT, Acta Physiol. Scand. 82, Suppl. 367, 69-93 (1971).

10. I. CREESE, D.R. BURT and S.H. SNYDER, Science 197, 596-598 (1977).

11. J.F.R. KÖNIG and R.A. KLIPPEL, The Rat Brain: A Stereotaxic Atlas of the Forebrain and Lower Parts of the Brain Stem, Williams and Wilkins, Baltimore (1963).

12. J.E. LEYSEN, W. GOMMEREN and P.M. LADURON, Biochem.Pharmacol. 27, 307316 (1978).

13. M.F. JARVIS and G.C. WAGNER, Neuropharmacology 24, 581-583 (1985).

14. G.A. RICAURTE, I. IRWIN, L.S. FORNO, L.E. DELANNEY, E.B. LANGSTON and J.W. LANGSTON, Brain Res. 403, 43-51 (1987).

15. K. CHIBA, A. TREVOR and N. CASTAGNOLI, Biochem. Biophys. Res. Comm. 120, 574-578 (1984).

16. R. HEIKKILA, A. HESS and R.C. DUVOISIN, Life Sci. 36, 231-236 (1985).

17. I. IRWIN, G.A. RICAURTE, L.E. DELANNEY and J.W. LANGSTON, Neurosci. Lett. 87, 51-56 (1988).

18. M.S. BENEDETTI and P.E. KEANE, J. Neurochem. 35, 1026-1032 (1980).

19. J.W. LANGSTON, I. IRWIN and L.E. DELANNEY, Life Sci. 40, 749-754 (1987). 